\title{
Trend of HIV-seropositivity among children in a tertiary health institution in the Niger Delta Region of Nigeria*
}

\author{
Daniel E Alikor ${ }^{1}$ and Nelson O. Erhabor. ${ }^{2^{*}}$ \\ 1. Department of Pediatrics. 2. Department of Hematology University of Port Harcourt \\ Teaching Hospital P.M.B. 6173 Port Harcourt, Nigeria. \\ *Author for Correspondence: e-mail:n_osaro@yahoo.com; Phone No.: 234-803-310 8233
}

\begin{abstract}
SUMMARY
The objective of the study was to investigate the recent trends and magnitude of pediatric HIV-infection in the Niger Delta of Nigeria. It is a descriptive study of 1,559 consecutively recruited children (0-16 years), in whom laboratory requests for HIV screening were made, and seen in the Pediatrics Department of the University of Port Harcourt Teaching Hospital between January 1999 to December 2004 were evaluated for HIV - infection. The overall prevalence obtained was $25.8 \%$. HIV-1 constituted the predominant viral serotype $(97.6 \%)$ compared to HIV-2 $(2.4 \%)$. The peak HIV seropositivity occurred in pediatrics 6-8 years. There was no statistically significant difference in prevalence rate based on gender $(O R=1, p=0.98)$. Children with clinical diagnosis of bronchopneumonia, neonatal sepsis, septicemia and pulmonary tuberculosis had higher prevalence of HIV seropositivity. There is a trend of increasing HIV prevalence from 1999 to $2004\left(\chi^{2}\right.$ for trend $\left.=6.23, p=0.39\right)$. History of previous blood transfusion was not significantly associated with $\mathrm{HIV}$ positivity $(\mathrm{OR}=0.94, p=0.94)$. This study shows that, in spite of the anti HIV campaign, there is a high prevalence of HIV among children attending tertiary health institution in the Niger Delta of Nigeria and the trend is increasing over the last 5 years. This calls for a re-intensified effort on health education and risk control programme, provision of antiretroviral regimen to prevent mother-to-child transmission of HIV, provision of supportive environment for voluntary counseling and confidential testing of pregnant women coupled with the provision of pediatric antiretroviral therapy to reduce HIV-related mortality and morbidity of HIV-infected Nigerian children.
\end{abstract}

*Published online before print

[ Afr J Health Sci. 2006;13: 80-85]

\section{Introduction}

There is no doubt that HIV/AIDS remains the greatest health problem worldwide. An estimated 40 million people are now living with HIV/AIDS, $95 \%$ of them in developing countries [1]. Conservative estimate indicate that 3 million children are currently living with HIV and about 3.8 million have already died of HIV before their $15^{\text {th }}$ birthday [2].

In Nigeria, the prevalence of HIV has increased steadily from $1.8 \%$ in 1991 to $5.0 \%$ in 2003 [3]. The vast majority of children born to HIV-infected mother acquire the virus in utero, at the time of labor and delivery or postnatally through breastfeeding [4-6].
Although prevention of mother-to-child transmission of HIV has been successful in the United States and Europe, due to the use of abbreviated antiretroviral regimens, all of these advances have had little impact in subSaharan Africa where paradoxically $>90 \%$ of the 3 million HIV-infected children currently live [7]. With less than $5 \%$ of pregnant women in resource-poor countries in sub-Saharan Africa having access to prenatal testing and preventive treatment, the burden of pediatric HIV infection is likely to increase in future [8]. Although a lot of work has been done in various part of the world on the extent and magnitude of pediatric HIV infection, there is 
paucity of data on pediatric HIV infection particularly in Nigeria. This study is therefore an attempt to investigate the recent trend in, and magnitude of, pediatric HIV-infection among children presenting to the Pediatric Department of the University of Port Harcourt Teaching Hospital and for which the clinician requested HIV screening.

\section{Materials and Methods}

The study was conducted at the University of Port Harcourt Teaching Hospital. This is a 500 bed tertiary hospital offering prenatal and pediatric care to residents in the cosmopolitan oil rich city of Port Harcourt. The city is in the heart of the oil and gas industry of the Niger Delta of Nigeria with a large population of migrant and expatriate workers from all parts of the world.

The subjects for this study consisted of 1599 consecutively recruited children aged 0 16 years out of a total of 27,0165 attending the Hospital within the study period of $1^{\text {st }}$ January 1999 to $31^{\text {st }}$ December 2004. To be included in the study, the child was aged $<16$ years, there should be a request for HIV screening by the pediatrician (following clinical suspicion) and the parents were willing to give informed consent. Written informed consent was obtained from the parents after counseling. An anonymous questionnaire regarding age, sex, history of blood transfusion was collected from the children's parents. The clinical diagnosis by the clinician at the time of presentation was also noted. The subjects were recruited from both the outpatient and inpatient departments of the Hospital.

\section{Sample processing and laboratory assay}

Whole blood was collected by venepuncture $(2 \mathrm{ml})$ into EDTA anticoagulated tubes and (2ml) into plain tubes without anticoagulant. All samples were screened using a double ELISA method as provided in the commercially available second generation Genscreen (Bio Rad, France) and Immunocomb (Orgenics, Israel) enzyme linked immunosorbent assay for the qualitative and differential diagnosis of HIV. Initially reactive samples to the double ELISA test were confirmed using the p24 antigen based test (Bio Rad, France). Children who exhibited a positive result to both tests were assumed to have been infected based on International standards for the diagnosis of HIV infection in infants [9].

\section{Statistical analysis}

All statistical analysis was carried out using the software SPSS (Version 9 Inc. Chicago, IL). Statistical analysis included descriptive statistics of mean and bivariate analysis of chisquare test. A p-value of $\leq 0.05$ was considered significant for all statistical comparisons.

\section{Results}

A total of 1599 children between $0-16$ years comprising of 787 females and 812 males, mean age $1.72 \pm 3.02$ years constituted the subjects for this study. Few parents (60) who initially declined their children being tested eventually gave informed consent after some sessions of pre-test counseling. The overall prevalence of HIV was $25.8 \%$. HIV-1 was the predominant viral serotype (97.6\%) compared to $2.4 \%$ for HIV-2. The age-specific HIV seroprevalence rate is shown in figure 1 . The peak HIV-seropositivity occurred in children 6-8 years $(31 \%)$. There was no statistically significant difference between seroprevalence in males and females with 203 of 787 males (25.7\%) and 209 of 812 females (25.8\%) being seropositive for HIV $(\mathrm{OR}=1, \mathrm{p}=0.98)$. The children with clinical diagnosis of bronchopneumonia, neonatal sepsis, septicemia and pulmonary tuberculosis, oral thrush and meningitis were found to have higher prevalence of HIV seropositivity as shown in table 1 . There was no statistically significant difference in the trended change in HIV prevalence over the 5 years under review $\left(\chi^{2}\right.$ for trend $\left.=6.23 ; p=0.39\right)$ as shown in figure 2. A previous history of blood transfusion was not associated with HIV positivity $(\mathrm{OR}=0.94 ; \mathrm{p}=0.58)$. 
RESEARCH ARTICLE

Figure I: Age-specific prevalence of HIV infection in Pediatrics

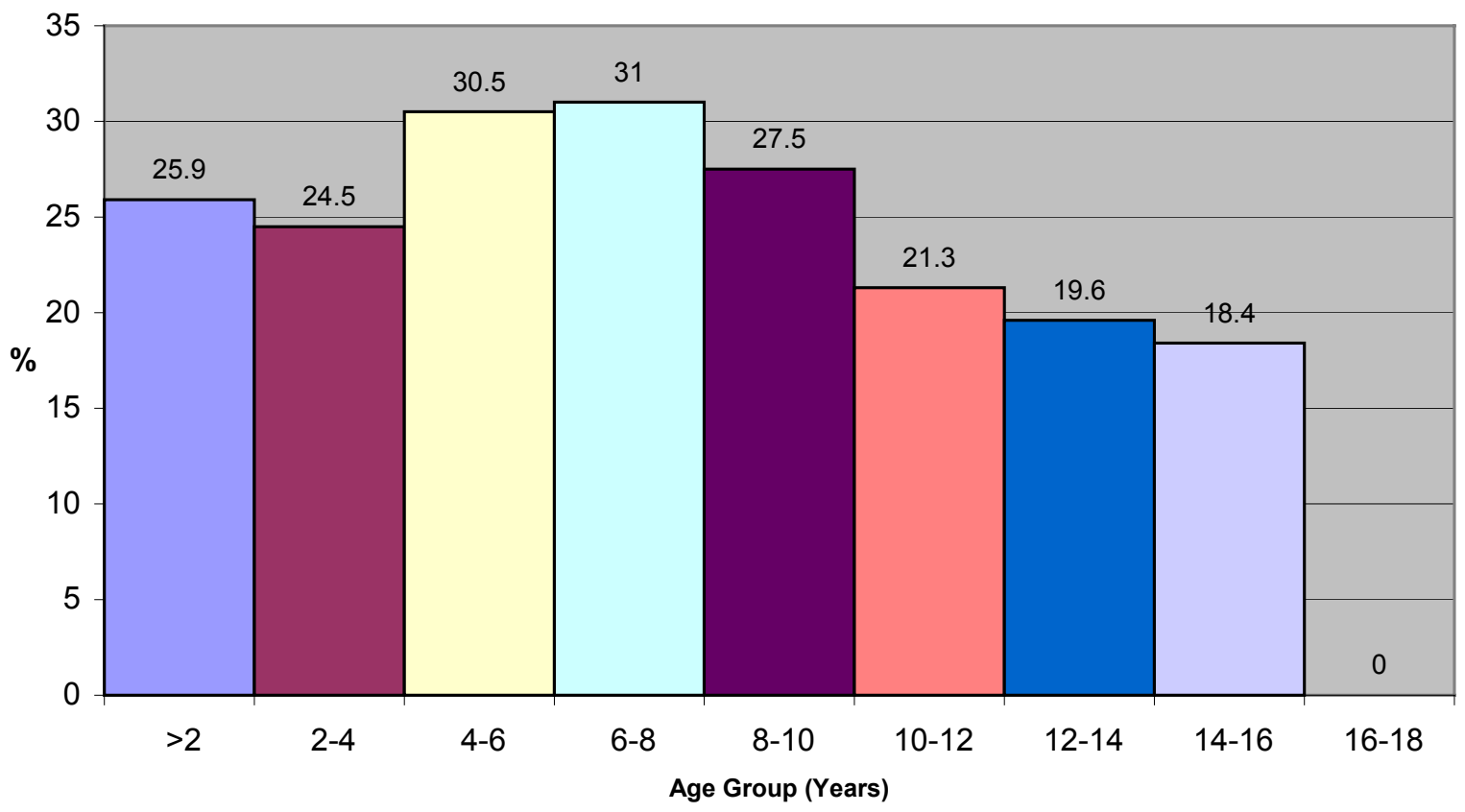

Table 1: Prevalence of HIV in pediatrics based on Clinical Symptoms

\begin{tabular}{|l|l|l|l|}
\hline Symptoms & Number Screened & Number Positive & \% Positive \\
\hline Low Birth Weight & 13 & 2 & 15.7 \\
\hline Neonatal Jaundice & 62 & 6 & 9.7 \\
\hline Neonatal sepsis & 29 & 15 & 51.7 \\
\hline Routine Screening & 29 & - & - \\
\hline $\begin{array}{l}\text { Pulmonary } \\
\text { tuberculosis }\end{array}$ & 105 & 47 & 44.8 \\
\hline Weight Loss & 117 & & \\
\hline Abandoned Babies & 70 & 31 & 26.5 \\
\hline Anemia & 42 & 19 & 27.1 \\
\hline Diarrhea & 87 & 2 & 4.8 \\
\hline Lymphadenopathy & 39 & 18 & 20.7 \\
\hline Malaria & 210 & 7 & 17.9 \\
\hline Meningitis & 23 & 7 & 3.3 \\
\hline Neuropathy & 17 & 8 & 34.8 \\
\hline Oral thrush & 11 & 3 & 17.6 \\
\hline Persistent Fever & 313 & 4 & 36.4 \\
\hline Pneumonia & 95 & 96 & 30.7 \\
\hline Rape & 13 & 53 & 55.8 \\
\hline Septicemia & 139 & 1 & 7.7 \\
\hline Others & 145 & 65 & 46.7 \\
\hline & & 28 & 19.3 \\
\hline
\end{tabular}




\section{RESEARCH ARTICLE}

Figure II: Trends in seroprevalence of HIV in Pediatrics (1999- 2004)

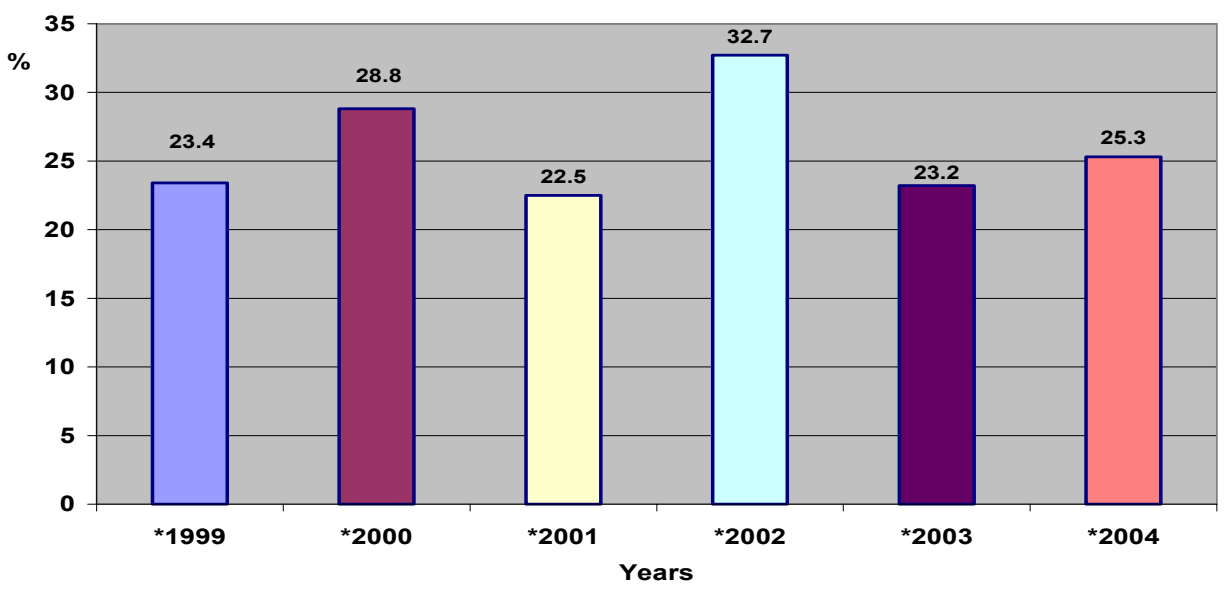

\section{Discussion}

The overall seroprevalence rate observed in this study among pediatrics was $25.8 \%$. This value is much higher than the national sentinel seroprevalence rate of $5.0 \%$ in 2003 [3] and prevalence's of $5.0 \%$ and $11 \%$ obtained in previous studies [10,11] among 1100 consecutively recruited children in Kinshasa and among 368 children $2-14$ years of age at Manayemo hospital Zaire. The higher prevalence obtained in this present study compared to that observed in the National sentinel seroprevalence report may be due to the fact that our study was carried out in a tertiary hospital and involved children for which there was already a high index of suspicion of HIV infection and brings to bare the fact that pediatric HIV infection among pediatrics residing in the Niger Delta of Nigeria is in explosion. Blood transfusion was not found to be significantly associated with HIV seropositivity. The observation of lack of significant association between history of previous blood transfusion and HIV positivity is discordant with previous report [10], which found history of previous blood transfusion a significant risk factor for HIV seropositivity among Zairian children. Although blood transfusion services in Nigeria is still at a suboptimal level and the national blood transfusion service is yet to be set up, the regular supply of highly sensitive and specific
HIV screening kits by the health ministry may be responsible for the reduced risk of transfusion-transmissible HIV infection in Nigeria. Since history of previous blood transfusion was not found to be significantly associated with HIV positivity among Nigerian children in this study, it becomes apparent that majority of HIV-infected children in Nigeria may have become infected through vertical transmission. While the reported rate of transmission of HIV from mother-to- child is as low as 1\% in Europe and North America, it is as high as $40 \%$ in some African and Asian studies [12,13] More than $90 \%$ of HIV infections in children result from mother-to-child transmission [14]. With the advent of routine antiretroviral regimen for the prevention of mother-to-child transmission of HIV in many developed countries, lower rates are now being described [15].

In this study we observed an increase in HIV prevalence from $23.4 \%$ in 1999 to $25.3 \%$ in 2004. This observation is consistent with report from the 2003 HIV seroprevalence sentinel report which showed that the prevalence of HIV in the adult population in Nigeria has increased from $1.8 \%$ in 1991 , to $3.8 \%$ in $1993,4.5 \%$ in $1996,5.4 \%$ in 1999 , $5.8 \%$ in 2001 and declined non-significantly to $5.0 \%$ in 2003(3). The main determinant of childhood infection is the scale and magnitude of HIV infection among the adult population. These figures suggest that, if this trend is 


\section{RESEARCH ARTICLE}

maintained, the burden of pediatric HIV infection and mortality in the Niger Delta in particular and Nigeria in general is likely to increase.

Preventive measures including the provision of antiretroviral regimen for the prevention of mother to child transmission, provision of supportive environment for voluntary counseling and confidential testing of pregnant women are advocated. There is also the need for International agencies to remain committed to the goals specified in the June 2001 declaration of the United Nation General Assembly special session on HIV/AIDS to reduce the proportion of infants infected with HIV by $20 \%$ by 2005 and $50 \%$ by 2010 . In order to reach these goals, a comprehensive strategy to prevent HIV infection in infants and young children should be developed and promoted in an integrated approach to health care delivery particularly in sub-Saharan Africa. These strategies should ideally consist of elements such as primary prevention of HIV infection in women and their partners, prevention of HIV transmission among HIV infected women, prevention of HIV transmission from women to their infants and young children, the provision of care, treatment and support for HIV infected women, their children and families.

In this study when symptomatology did exist in children seropositive for HIV, bronchopneumonia, neonatal sepsis, septicemia and pulmonary tuberculosis, oral thrush and meningitis were the commonest presentations. These clinical features associated with HIV seropositivity are similar to those listed in the $\mathrm{CDC}$ revised classification system for human immunodeficiency virus infection in children [16]. We found HIV-1 the predominant viral serotype responsible for pediatric HIV infection in the Niger Delta of Nigeria. This observation is cordant with previous reports $[17,18]$ that found HIV-1 the predominant viral strain in Nigeria.

\section{Conclusion}

This study found a trend of increasing prevalence of HIV seropositivity in children in our study area between 1999 and 2004. We advocate that community-based epidemiological studies should be done in order to determine the prevalence of HIV seropositivity in the general pediatric population. Implementation of standard preventive measures especially health education/risk control programs and measures aimed at preventing mother-to-child transmission of HIV is recommended.

\section{References}

1. Piot $\mathrm{P}$ and Coll-Seck A. Preventing mother to child transmission of HIV in Africa. Bulletin of World Health Organization. 1999; 77: 869-70

2. Joint United Nations Programme on HIV/AIDS, World Health Organization. Report on global HIV/AIDS epidemic. Geneva, Switzerland. World Health Organization, July 2002.

3. Federal Ministry of Health. Summary findings from the 2003 National HIV seroprevalence sentinel survey in Nigeria. Information for Policy Makers. 2004: pp12-38.

4. Langston C, Lewis DE, Hammill HA, Popek EJ, Kozinetz CA, Kline MW, Hanson IC and Shearer WT. Excess intrauterine fetal demise associated with maternal human immunodeficiency virus infection. Journal of Infectious Diseases 1995; 172: 1451-1460.

5. Viscarello RR, Cullen MT, DeGennaro NJ and Hobbins JC. Fetal blood sampling in HIV- sero- positive women before elective midtrimester termination of pregnancy. American Journal of Obstetrics and Gynecology. 1992; 167: 1075-1079.

6. Mofenson LM. Interaction between the timing of perinatal human immunodeficiency virus infection and design of preventive and therapeutic interventions. Acta of Paediatrica. 1997; 421: $1-9$.

7. Decock KM, Fowler MG, Mercier E, de Vincenzi I, Saba J, Hoff E, Alnwick DJ, Rogers $M$ and Shaffer N. Prevention of mother-to-child HIV transmission in resource-poor countries: translating research into policy and practice. Journal of American Medical Association. 2000; 283: $1175-1182$.

8. Dabis F and Ekpini ER. HIV-1/ AIDS and maternal and child health in Africa. Lancet. 2002; 359: 2097-2104. 


\section{RESEARCH ARTICLE}

9. Alioum A, Dabis F, Dequae- Merchadou L, Haverkamp G, Hudgens M, Hughes J, Karon J, Leroy V, Newell ML, Richardson $\mathrm{B}$ and Weverling GJ. Estimating the efficacy of interventions to prevent mother - Child transmission of HIV in breast-feeding populations: development of a consensus methodology. Statistics in Medicine. 2001; 20:3539-3556.

10. Shaffer N, Hedberg K, Davachi F, Lyamba B, Breman JG, Masisa OS, Behets F, Hightower A and Nguyen-Dinh P: Trends and risk factors for HIV-1 seropositivity among outpatient children, Kinshasa Zaire. AIDS. 1990; 4 1231-1236.

11. Mann JM, Francis H, Davachi F, Baudoux P, Quinn TC, Nzilambi N, Bosenge N, Colebunders RL, Kabote $\mathrm{N}$ and Piot P. Human immunodeficiency virus seroprevalence in pediatric patients 2-14 years of age at Mama Yemo Hospital, Kinshasa Zaire. Pediatrics. 1986; 78:673 677.

12. Mode of delivery and risk of vertical transmission of human immunodeficiency virus type 1- a meta- analysis of 15 prospective cohort studies. The International Perinatal HIV Group. New England Journal of Medicine. 1999; 340: 977- 987.

13. Rates of Mother-to-child Transmission of HIV-1 in Africa, America and Europe: Results from 13 perinatal studies. Working Group on Mother-to-child Transmission of HIV. Journal of Acquired Immune Deficiency Syndrome and Human Retrovirology. 1995; 8:506-510.

14. Fowler MG, Melnick SL and Mathieson BJ. Women and HIV epidemiology and global overview. Obstetrics and Gynecology Clinic of North America 1997; 24:705-729.

15. Reggy A, Simonds RJ and Rogers M. Preventing perinatal HIV transmission. AIDS. 1997; 11:s61-67.

16. Center for Disease Control (CDC). Revised classification system for human immunodeficiency virus infection in children less than 13 years of age. Mortality and Morbidity Weekly Report. 1994; 43: 1-10

17. .Ejele OA, Nwauche CA and Erhabor O. The prevalence of hepatitis B surface antigenaemia in HIV positive patients in the Niger Delta of Nigeria. Nigerian Journal of Medicine. 2004; 13:175-179.

18. Akinsete I, Akanmu AS and Okany CC. Trends in HIV sero-positivity among visa applications in Lagos, Nigeria: A five-year survey 1992-1996. Nigerian Postgraduate Medical Journal. 1998; 5: 69 -72. 